\title{
Do fast food restaurants cluster around high schools? A geospatial analysis of proximity of fast food restaurants to high schools and the connection to childhood obesity rates
}

\author{
Hilary Nixon ${ }^{\mathrm{a}}$ and Lauren Doud ${ }^{\mathrm{b}}$
}

Submitted 25 April 2011 / Accepted 25 July 2011 / Published online 25 October 2011

Citation: Nixon, H., \& Doud, L. (2011). Do fast food restaurants cluster around high schools? A geospatial analysis of proximity of fast food restaurants to high schools and the connection to childhood obesity rates. Journal of Agriculture, Food Systems, and Community Development, 2(1), 181-194. http://dx.doi.org/10.5304/jafscd.2011.021.007

Copyright (C) 2011 by New Leaf Associates, Inc.

\begin{abstract}
Nationwide, approximately $30 \%$ of children consume fast food on a typical day, and caloric intake from fast food has increased fivefold over the past three decades. Our analysis adds to a growing body of public health and planning research through a geospatial analysis of fast food restaurants in Santa Clara County, California. We selected 41 high schools, representing $97 \%$ of enrollment in the county, and examined proximity to fast food restaurants within 400 meters (437 yards) and 800 meters (875 yards) of the schools. Our results indicate that fast food restaurants are clustered near high schools with higher obesity rates. In addition, observation of student behavior suggests that many students patronize these establishments after school and often make poor nutritional choices,

${ }^{a}$ Corresponding author: Associate Professor, Department of Urban and Regional Planning, San Jose State University, San Jose, CA 95192-0185 USA; +1-408-924-5852; hilary.nixon@sjsu.edu

b GIS Specialist, Insignia Environmental, Palo Alto, CA 94301 USA; +1-650-321-6787 x235; lrdoud@gmail.com
\end{abstract}

consuming from $30 \%$ to $75 \%$ of the daily recommended allowance of calories for teens in a single after-school snack. Since there appears to be a relationship, albeit complex, between the built environment and public health, there also is an opportunity to develop more effective planning policies and programs to encourage active behavior and healthy eating choices.

\section{Keywords}

built environment, children, ethnicity, fast food restaurants, geospatial analysis, obesity, planning, public health

\section{Introduction}

Americans spend nearly US $\$ 200$ billion annually on fast food (U.S Census, 2010). Since 1992, sales at limited-service eating establishments including fast food restaurants have increased by $46 \%$ (in constant US 2010 dollars; see Figure 1) (U.S Census, 2010). Two-thirds of adults and $16 \%$ of children are overweight or obese, and $30 \%$ of U.S. children consume fast food in a typical day (Hedley, Ogden, Johnson, Carroll, Curtin, \& Flegal, 2004; Simon, 
Figure 1. Annual Sales at Limited Service Eating Establishments, 1992-2008, in 2010 US Dollars

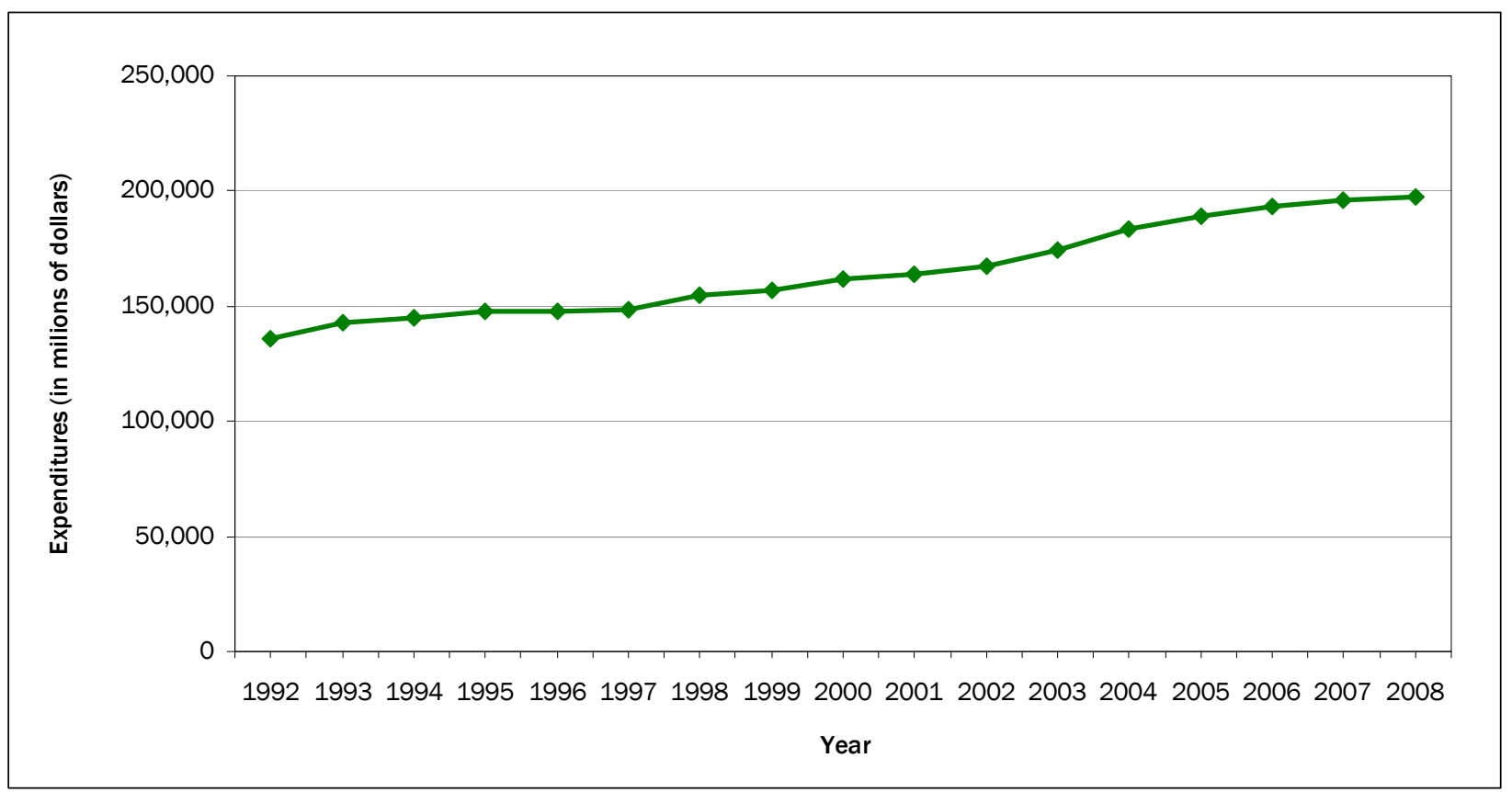

Source: U.S. Census Bureau. (2010). Estimated annual sales of U.S. retail and food services firms by kind of business: 1992 through 2008. Retrieved from http://www2.census.gov/retail/releases/historical/arts/2008 ARTS.pdf

Kwan, Angelescu, Shih, \& Fielding, 2008). Children's daily caloric intake from fast food increased fivefold (from $2 \%$ to $10 \%$ of the daily recommended allowance of calories) between the late 1970s and the mid-1990s, while at the same time, school-age youth were becoming less physically active (Guthrie, Lin, \& Frazao, 2002; McMillan, 2009). The human health impacts associated with unhealthy food consumption and lack of exercise are substantial. In fact, deaths attributed to poor diet and physical inactivity are second only to tobacco among preventable deaths in the U.S. (Mokdad, Marks, Stroup, \& Gerberding, 2004, 2005). The economic impacts of obesity are also staggering. Finkelstein, Trogdon, Cohen, and Dietz (2009) estimate that direct medical costs associated with obesity are US $\$ 147$ billion annually. If obesity patterns continue, estimates suggest that by 2018, annual obesity-related medical expenses will total US $\$ 344$ billion, approximately $21 \%$ of total annual health-care spending, compared to estimates of approximately $9 \%$ today (Hellmich, 2009).

Eating patterns developed in childhood tend to persist into adulthood, and research finds that the food and beverage industry aggressively targets this demographic (Story \& French, 2004). A growing body of literature focuses on the proximity of fast food establishments to schools. ${ }^{1}$ Currie, DellaVigna, Moretti, and Pathania (2009) found a $5.2 \%$ increase in obesity rates among ninth graders when a fast food restaurant was located within one tenth of a mile $(0.2 \mathrm{~km})$ of their school. Similarly, Davis and Carpenter (2009) found that students with fast food restaurants within one-half mile $(0.8$ $\mathrm{km})$ of their school were less likely to eat fresh fruits and vegetables, consume more soda, and were more likely to be overweight or obese.

Increasingly, geographic information systems (GIS) are employed as a methodological tool to assess

\footnotetext{
${ }^{1}$ Some excellent articles in this field include Austin et al., 2005, Currie, DellaVigna, Moretti, \& Pathania, 2009; Davis \& Carpenter, 2009; Nielson, Siega-Riz, \& Popkin, 2002; Neumark-Sztainer, French, Hannan, Story, and Fulkerson, 2005; Simon et al., 2008; Sturm, 2008; and Zenk \& Powell, 2008, among others.
} 
proximity to fast food outlets and the relationship to obesity (see, for example, Day \& Pearce, 2011; Howard, Fitzpatrick, \& Fulfrost, 2011). The current research study complements the literature through a spatial analysis of formula-based fast food restaurants with a national footprint and high schools in Santa Clara County, California. ${ }^{2}$ We focus particularly on the proximity of fast food restaurants to schools and the linkage to student health, including obesity, as assessed through student performance on California's Physical Fitness Test. In addition, we conduct limited ethnographic observational research to better understand some of the after-school eating behaviors at fast food restaurants located near schools. To date, the number of qualitative studies examining teenagers' eating behaviors is limited. Neumark-Sztainer, Story, Perry, and Casey (1999) conducted focus group discussions with teens to examine the factors that influence food choices. We are not familiar, however, with any study that has conducted ethnographic or unobtrusive observational research of teens' eating behaviors at fast food outlets. This approach provides additional insight into these behaviors beyond what can be captured using other methods (most notably, surveys).

Increasingly, studies have suggested various policy interventions, including zoning regulations, to limit the availability of fast food and promote access to healthy food alternatives that could reduce the obesity epidemic in the United States (Ashe, Feldstein, Graff, Kline, Pinkas, \& Zellers, 2007; Ashe, Jernigan, Kline, \& Galaz, 2003; Samia Mair, Pierce, \& Teret, 2005). Obesogenic environments describe land use patterns that do not support physical activity and healthy eating opportunities, and, therefore contribute to obesity (Black \& Macinko, 2008; Cummins, Petticrew, Higgins, Findlay, \& Sparks, 2005; Maddock, 2004; White,

\footnotetext{
2 "Formula-based" indicates standardized features whose appearance is identical to other restaurants in the chain (e.g., menu, employee uniforms, architectural design, décor, or signage). "Fast food" refers to inexpensive food prepared and served quickly to consumers that tends to be high in fat and low in nutritional value. "National footprint" describes any restaurant with outlets in more than one state.
}

2007). One facet that defines obesogenic environments is access to unhealthy food, such as fast food restaurants (Simon et al., 2008). It should be noted that while healthy alternatives are available at fast food outlets (just as unhealthy choices are available at the finest dining establishments), the fast food industry generates the majority of its revenues from products that contain excessive amounts of fat, calories, and sugar (Stein, 2006).

Lifelong eating habits are often established during childhood. Therefore, in order to design and implement effective policy instruments, a more complete understanding of the food environment and eating behavior around secondary schools is key. Although this research focuses on a single county in California, the results are likely to be of much broader interest to public health professionals, school administrators, and planners in similar urbanized areas across the United States. Santa Clara County is ideally suited for this study because it shares many demographic characteristics with the overall California and U.S. population (see table 1). However, while Santa Clara County has many similarities, it is actually the differences that make this an ideal location to study issues related to childhood obesity. In particular, Santa Clara County is a majority non-White population. Several studies have shown a link between ethnicity, income, and obesity, and understanding how these dynamics play out in the local school food environment in Santa Clara County is likely to be of interest to a wide range of professionals and researchers.

The rest of this paper is structured as follows. In the next section, we describe our study area and present detailed information about our study schools. This is followed by a brief description of the process used to identify the fast food restaurants for our analysis. Then we present our geospatial analysis methods and discuss our results, followed by a presentation of our ethnographic observation research and results. Finally we conclude with a discussion of some policy approaches designed to promote healthy eating and active behavior. 
Table 1. Comparison of Selected Demographic and Socioeconomic Characteristics of Santa Clara County, California, and the U.S. Population, 2010

\begin{tabular}{lccc}
\hline Variable & Santa Clara County & California & U.S. \\
\hline Persons under 5 years (\%) & 7.5 & 7.5 & 6.9 \\
\hline Persons under 18 year old (\%) & 24.4 & 25.5 & 24.3 \\
\hline Persons 65 year old and over (\%) & 10.9 & 11.2 & 12.9 \\
\hline High school graduates, age 25+ (\%) & 85.8 & 80.5 & 84.6 \\
\hline Median household income, 2009 (US\$) & 84,990 & 58,925 & 50,221 \\
\hline Persons below poverty level (\%) & 9.1 & 14.2 & 14.3 \\
\hline White persons (\%) & 47.0 & 57.6 & 72.4 \\
\hline Black persons (\%) & 2.6 & 6.2 & 12.6 \\
\hline Asian persons (\%) & 32.0 & 13.0 & 4.8 \\
\hline Persons of Hispanic or Latino origin (\%) & 26.9 & 37.6 & 16.3 \\
\hline
\end{tabular}

Source: U.S. Census Bureau: State and County QuickFacts. Data derived from Population Estimates, Census of Population and Housing, Small Area Income and Poverty Estimates.

\section{Study Area: Santa Clara County, California}

Santa Clara County is located in the heart of Silicon Valley in Northern California. Extending over an area of nearly 1,300 square miles (3,400 square $\mathrm{km})$, the county is home to approximately 1.78 million people (U.S. Census, 2011). In 2008, there were approximately 60,000 students enrolled in 12 public high school districts throughout the county. Santa Clara County is of particular interest for this research as approximately $20 \%$ of children ages 5 to 19 are overweight, compared to $13 \%$ statewide and 15\% nationally (Santa Clara County, 2005; U.S. Department of Health and Human Services, 2005).

For the purposes of this analysis, we focused on a subset of 41 public high schools in Santa Clara County, representing approximately $50 \%$ of all high schools and $97 \%$ of total enrollment (see figure 2). School data (see table 2) for Santa Clara County were obtained from the California Department of Education (CDE), including enrollment, student and parent demographic characteristics, National School Lunch Program (NSLP) participation rate, and whether the school maintained an open or closed campus policy for the 2007-2008 academic year (CDE, n.d.). Schools with open campus policies allow student to leave campus during lunch hours. To date, no research appears to have examined open/closed campus policies status with food consumption patterns and resultant obesity rates.

In addition, we collected data on student performance on the California Physical Fitness Test. The California Physical Fitness Test is administered to all fifth, seventh, and ninth graders in the state and assesses the following six fitness measures: aerobic capacity, abdominal strength and endurance, upper body strength and endurance, body composition (i.e., body fat measurement and body mass index, or BMI), trunk extensor strength and flexibility, and flexibility (CDE, n.d.). The Cooper Institute developed "healthy fitness zones" (HFZ) for each of the six measures, and children are designated as either within or not within an HFZ. Those schools that did not meet the minimum fitness-testing threshold of having at least 10 students' results reported were excluded from our study; this included all of the alternative education facilities in the county. All data are aggregated to the school level to protect individual privacy. These data were secured in order to allow us to examine the possible statistical correlation between key characteristics (e.g., student race and ethnicity, parents' education level, etc.) and the percent of students not within the HFZ. In addition, these 
Figure 2. Map of Study Area's High Schools and Fast Food Restaurants

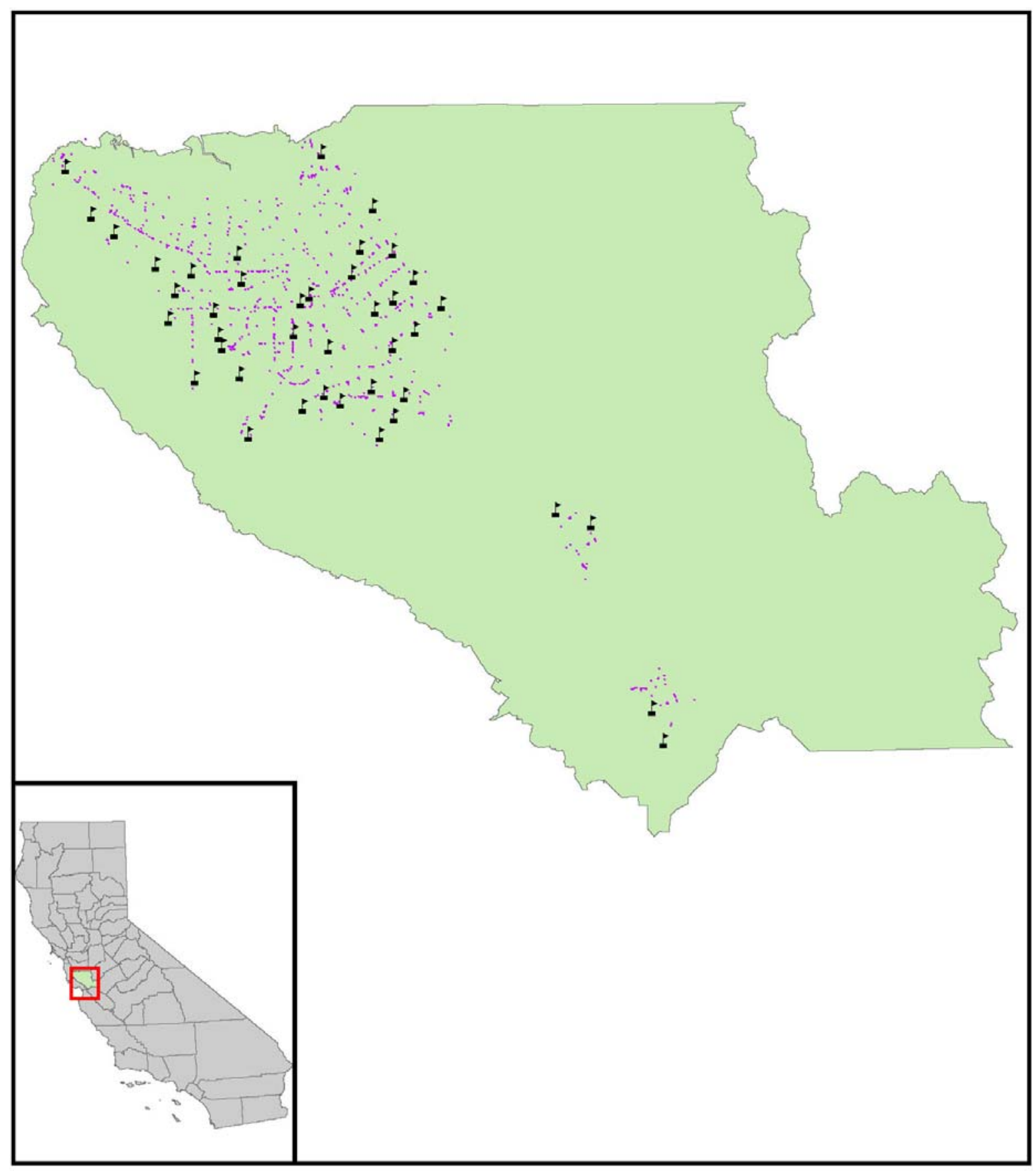

\section{Study Area Map}

- High School

Fast Food Outlet

Santa Clara County

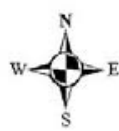

$1: 475,000$

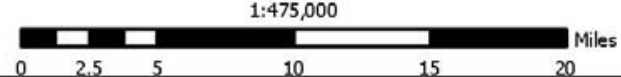


Table 2. Summary Statistics for Schools

\begin{tabular}{|c|c|c|c|c|}
\hline Variable & Average & Range & $\begin{array}{l}\text { Standard } \\
\text { Deviation }\end{array}$ & $\begin{array}{l}\text { Pearson Corr. } \\
\text { Coef. (w/Not } \\
\text { Within HFZa) }\end{array}$ \\
\hline Not within the Healthy Fitness Zone (\% of students) & 25.6 & $8.4-47.3$ & 9.6 & n.a. \\
\hline Open or closed school policy ( $0=$ open, $1=$ closed $)$ & 0.78 & $0-1$ & 0.42 & $0.56 * *$ \\
\hline National School Lunch Program (\% of students) & 27.3 & $0-64$ & 19.9 & $0.73 * *$ \\
\hline Total school enrollment & 1,384 & $65-2,664$ & 479 & - \\
\hline \multicolumn{5}{|l|}{ Student race/ethnicity (\% of students) } \\
\hline American Indian & $<1$ & $0-2$ & 0.59 & $0.38 *$ \\
\hline Asian & 23 & $1-75$ & 18.7 & $-0.55 * *$ \\
\hline Black & 3.5 & $0-10$ & 2.04 & 0.17 \\
\hline Filipino & 4.7 & $0-22$ & 5.16 & 0.17 \\
\hline Hispanic/Latino & 35.9 & $2-96$ & 24.4 & $0.80 * *$ \\
\hline Pacific Islander & 0.63 & $0-2$ & 0.7 & 0.02 \\
\hline White & 30.4 & $1-81$ & 20.5 & $-0.50 * *$ \\
\hline Gifted and Talented Education Program (\% of students) & 12.9 & $0-32$ & 6.9 & -0.22 \\
\hline \multicolumn{5}{|l|}{$\begin{array}{l}\text { Parent Education Level (\% of students with parents } \\
\text { with the specified education level) }\end{array}$} \\
\hline Not a high school graduate & 15.7 & $1-56$ & 14.6 & $0.72 * *$ \\
\hline High school graduate & 17.6 & $1-36$ & 9.7 & $0.71 * *$ \\
\hline Some college & 20.3 & $3-36$ & 8.6 & $0.42 *$ \\
\hline College graduate & 24.4 & $6-40$ & 8.9 & $-0.44 * *$ \\
\hline Graduate school & 22.0 & $1-68$ & 21.1 & $-0.81 * *$ \\
\hline
\end{tabular}

Notes:

a HFZ refers to Healthy Fitness Zone

* and ** represent statistical significance at the $p<0.05$ and $p<0.01$ levels.

Source: California Department of Education.

data were used to identify the targeted schools for our ethnographic research.

On average, one quarter of students participating in the California Physical Fitness Test fell outside the range for the Healthy Fitness Zone. Since body composition is only one component of the testing, this does not mean that all students not within an HFZ are overweight or obese, but there is a strong relationship between the two. We see quite a range across the schools in the percent of students not within an HFZ. At the upper end, at San Jose High Academy, $47 \%$ of students tested were not within an HFZ, while only $8 \%$ of students at Los Gatos High School fall into this range. Although we did not collect household income data for the schools, it is interesting to note that San Jose High Academy is located in one of the lowest income communities in the county, while Los Gatos High School is in one of the highest income areas. Existing research on the relationship between income and obesity finds that lower-income neighborhoods experience much higher rates of obesity, often due to fewer opportunities for physical activity and reduced access to healthy food resources (Black \& Macinko, 2008).

In order to better understand some of the educational and demographic factors that may have an influence on health, we computed the Pearson correlation coefficient between the percent of students not within an HFZ and a range of school-specific 
and student and family demographic characteristics shown in table 2 . This type of bivariate analysis cannot tease out the joint influence of multiple variables, but it does provide the opportunity to discover what some of the underlying significant relationships might be. We find statistically significant relationships between many of our variables and percent of students not within an HFZ.

Not surprisingly, we see a strong relationship between race and ethnicity and HFZ. There is a positive correlation between the percent of students with American Indian or Hispanic/Latino heritage and percent of students not within an HFZ. By contrast, a negative correlation exists for the percent of Asian or White students and HFZ. This confirms findings from other studies on obesity levels among different ethnic groups; higher rates of being overweight and obesity have been found for Latino, African American, and American Indian and Alaskan Native youth (Robert Wood Johnson Foundation, 2010).

We also find a significant relationship between parents' education levels and the percent of students not within an HFZ. Schools where a larger percentage of students were not within an HFZ were

Table 3. Fast Food Restaurants in Santa Clara County, By Type

\begin{tabular}{lcc}
\hline Type & Count & Percent \\
\hline Hamburger & 240 & $22.5 \%$ \\
\hline Sandwich & 164 & $15.3 \%$ \\
\hline Pizza & 138 & $12.9 \%$ \\
\hline Coffee & 136 & $12.7 \%$ \\
\hline Convenience & 99 & $9.3 \%$ \\
\hline Mexican & 92 & $8.6 \%$ \\
\hline Dessert & 88 & $8.2 \%$ \\
\hline Fried Chicken & 44 & $4.1 \%$ \\
\hline Chinese & 23 & $2.2 \%$ \\
\hline Hot Dog & 23 & $2.2 \%$ \\
\hline BBQ & 15 & $1.4 \%$ \\
\hline Bagel & 7 & $0.7 \%$ \\
\hline Total & 1,069 & $100.0 \%$ \\
\hline
\end{tabular}

also more likely to have a higher percentage of parents with lower levels of formal education. Alternatively, higher levels of parental education were negatively correlated with the percent of students not within an HFZ. There does not appear to be a large body of existing research specifically on this topic, although a 2005 study in Germany (Lamerz et al.) found that higher rates of childhood obesity were associated with lower parental education levels. In the U.S., a study by Variyam (2001) found that parents' nutrition knowledge is associated with obesity levels among children. Additionally, there is strong evidence to suggest that income and education are related (U.S. Bureau of Labor Statistics, 2011) and, as noted above, income and obesity are correlated.

\section{Identifying Fast Food Restaurants}

In order to develop a comprehensive database of all formula-based fast food restaurants with a national footprint, data was obtained first from the Santa Clara County Department of Environmental Health (SCCDEH). All retail food facilities are routinely inspected by SCCDEH, and restaurant inspection records are available online through a third-party data provider (Decade Software Company). The SCCDEH data was crossreferenced with Yellowpages.com, as its online records only list those restaurants inspected within the past year. A total of 1,069 qualifying fast food restaurants were identified (see figure 2 for their physical locations) and they are summarized in table 3 based on the general category of food served.

\section{Geospatial Analysis and Results}

All geographic analysis for this research was performed using ArcGIS 9.2 software. The process can generally be summarized into six distinct processes. First, public schools and fast food outlets were geocoded by address using Batchgeocode. com, a free online service that converts address data to latitude and longitude coordinates. Second, using the ArcGIS Network Analyst extension, a network dataset was created to generate 400-meter and 800-meter service areas around each school. Third, the density of fast food outlets within the 400-meter and 800-meter secondary-school food 
environments was calculated to quantify the degree of fast food outlet concentration. These distances have been used in several studies to approximate five-minute and 10-minute walks, respectively (Austin et al., 2005; Simon et al., 2008). Density was calculated as the number of outlets per acre within 400-meter and 800-meter service areas. Fourth, a Closest Facility analysis identified the closest fast food outlet to each school to assist with restaurant selection for observational research. Fifth, a second Closest Facility analysis was run to measure the streetline distance from each fast food outlet to the closest high school. This additional output variable, the distance from each fast food outlet to school, was used as an input variable to conduct spatial autocorrelation analysis. Lastly, the degree of clustering of fast food outlets near schools with higher obesity rates (defined as percent of students not within the HFZ) was assessed using ArcGIS's Spatial Autocorrelation (Moran's I) Tool. This tool measures whether a spatial pattern is clustered, dispersed, or random and calculates a Moran's I Index value. Values greater than zero indicate the presence of clustering. To simulate the urban environment, we selected a Manhattan grid, rather than a Euclidean distance, in ArcGIS to determine adjacency (i.e., whether the fast food outlet and high school are "neighbors" or not) for the spatial autocorrelation analysis.

\section{Results}

The mean density of fast food outlets within the 400-meter and 800-meter service areas was 0.61 and 3.29 outlets per acre, respectively. Of the schools included in this analysis, nearly $60 \%$ had at least one fast food outlet within 800 meters of campus, which is comparable to existing research in California. Simon et al. (2008) found that 64.8\% of schools in Los Angeles County had at least one fast food outlet within 800 meters, while Davis (2008) noted that $55 \%$ of all middle and highschool students in California were within 800 meters of at least one fast food outlet. Interestingly, our results, and existing California results, are noticeably higher than the nationwide average of $33 \%$ of schools with one fast food outlet within 800 meters (Zenk \& Powell, 2008).
To further explore the relationship between obesity rates and density of fast food outlets in close proximity to high schools, we looked for spatial clustering and assessed this relationship using the Moran's I value. For both the 400-meter and 800meter service areas, our results indicate that spatial clustering is present. Within the 400 -meter service area, the Moran's I index value was 1.45 , significant at the $\mathrm{p}<0.01$ level of significance. The value for the 800 -meter service area was 0.37 , significant at the $\mathrm{p}<0.05$ level of significance. These results indicate that there is a significant geospatial clustering relationship between obesity rates (as measured by percent of high school students not within the HFZ) and the proximity of fast food outlets. However, these results cannot determine why this geospatial pattern exists. Several studies have hypothesized that the level of commercialization in close proximity to schools, especially high schools, is a likely reason (Austin et al., 2005; Simon et al., 2008). What is particularly interesting about our finding is that we do not only examine whether there is an unusually large number of fast food outlets located near schools, which can logically be connected to levels of commercialization, but also we specifically connect this to students' fitness levels. In schools where a greater percent of students are not within an HFZ, there are more fast food outlets. A similar study, using a different methodological approach, by Davis and Carpenter (2009) finds similar results, lending confidence to our conclusion.

\section{Ethnographic Student Observation Analysis and Results}

In addition to our geospatial analysis, we were interested in better understanding some of the eating habits of high school students. Several studies have surveyed students on their food choices (see, e.g. French, Story, Neumark-Sztainer, Fulkerson, \& Hannan, 2001; Nielsen et al., 2002; Neumark-Sztainer et al., 2005; Neumark-Sztainer, 2009) but these methods rely on self-reporting, and the literature has consistently found errors of omission and commission when individuals self-report their behavior. Ethnographic observation can more accurately capture behavioral data than other qualitative behavioral studies. This is due to its 
unobtrusive nature, as participants are unaware that their behavior is under observation (Bernard, 2002). However, this type of research is timeconsuming and costly. Due to limited resources, we only were able to conduct observation at four schools; additional research is warranted to confirm our findings.

We selected our sites for observation based on the school obesity data and number of fast food restaurants within 800 meters. The two campuses with the most fast food outlets and highest obesity rates and the two with the fewest outlets and highest obesity rates were selected for this part of our study. A Closest Facility analysis, partnered with on-site ground-truthing, was used to select the fast food outlets for observation. Table 4 summarizes our study locations.

The ethnographic observation took place on weekdays immediately following the end of the school day for a period of approximately 30 minutes. The intent was to capture the "after-school snacking" behavior of high school students. The researcher was seated at a location in the fast food outlet that allowed him or her to record the items purchased by the students without notice. Students from the local high school were identified using the best judgment of the researcher and included a combination of factors including age, attire (e.g., logoed apparel, backpacks, etc.), and, when audible, conversations by the subjects. A chart was used to track and record all purchases. Nutrition information readily available from the establishment's main corporate website was then used to calculate the total calorie and fat consumption.

\section{Results}

Our results for after-school snacking behaviors at each of the four sites selected are summarized in table 5. Average total calories consumed ranged from 520 (at the coffee house) to 1,371 (at the pizza outlet), representing as much as $57 \%$ of the total daily recommended allowance for 14 to 18 year olds and as much as $75 \%$ of total daily recommended allowance for fat grams. In addition to our analysis of the food orders, we observed some additional noteworthy student eating behaviors. At the hamburger outlet, items from the value menu were extremely popular. In fact, of the seven subjects who were observed, six purchased items exclusively from the value menu. In addition, although not a focus for our study as we could not observe the specific orders, we noticed a large number of drive-through customers who appeared to be mothers picking up their children after school. Large, foot-long subs were popular at the sandwich shop. In addition, although the sandwich shop had clearly identified lower-calorie, healthier options, students tended to order higher calorie sandwiches with all of the trimmings (e.g., mayonnaise, cheese, etc.). Purchasing behavior at the coffee shop was even more striking. All seven subjects purchased large, blended drinks ( 5 coffeebased, 2 tea beverages) and all ordered their beverage with whipped cream. In addition, it appeared that the students were regular patrons, as the baristas knew the customers by name.

Although our results are from a small number of sites and therefore it is impossible to generalize or make broad conclusions, certain elements warrant discussion and may prompt more in-depth

Table 4. Summary of Schools for Ethnographic Observation

\begin{tabular}{lcccc}
\hline School & \% Not Within HFZ & $\begin{array}{c}\text { Number of Fast } \\
\text { Food Outlets (800m) }\end{array}$ & $\begin{array}{c}\text { Fast Food Outlet Type } \\
\text { for Observation }\end{array}$ & $\begin{array}{c}\text { Distance Between School } \\
\text { and Fast Food Outlet }\end{array}$ \\
\hline San José High Academy & $47.3 \%$ & 1 & Pizza & $540 \mathrm{ft} .(165 \mathrm{~m})$ \\
\hline Overfelt High School & $38.4 \%$ & 1 & Coffee house & $1,606 \mathrm{ft} .(490 \mathrm{~m})$ \\
\hline Prospect High School & $27.4 \%$ & 12 & Hamburger & $1,835 \mathrm{ft} .(559 \mathrm{~m})$ \\
\hline Cupertino High School & $15.3 \%$ & 9 & Sandwiches & $1,531 \mathrm{ft} .(467 \mathrm{~m})$ \\
\hline
\end{tabular}


research. Our results suggest that high school students are patronizing these fast food establishments after school and they are often consuming large quantities of calories, typically in excess of one third of their total daily recommended allowance and more than one half of their daily recommended allowance for fat calories.

Our research methods do not allow us to determine what these students consume during other parts of the day, but our assumption is that these meals are considered after-school snacks, and that it is highly likely that the student consumed breakfast and/or lunch earlier in the day and is likely to consume dinner later in the evening. In the case of visits to nearby coffee houses, there is no doubt that the single beverage is not replacing a meal, yet it represents nearly $25 \%$ of the total recommended calorie and fat consumption the student should have during an entire day. In addition, while the hamburgers, sandwiches, and pizza did contain protein and vegetables, the coffee beverage has little nutritional value. Our research methods did not allow us to assess how regularly students consume coffee; however, evidence suggests that a growing number of children are drinking coffee, particularly high-fat, blended coffee drinks (Swain, 2011).

We specifically selected the four school sites based on concentration of fast food outlets relative to obesity rates (high obesity rates and either high or low concentration of fast food outlets) to see if there was any difference in eating behaviors. Our limited study did not reveal any particular patterns. Further research using a wider range of sites and more in-depth study of eating behaviors is warranted.

\section{Conclusions and Policy Recommendations}

While many argue that patronizing a fast food outlet is a personal choice, there are neighborhoods where the only choice is a fast food outlet, and/or where access to fresh, healthy food is extremely limited. A principle tenet of city planning is to protect the public's health; therefore, there is legal precedence to regulate the fast food industry and engage in community land use planning that supports physical activity and healthful eating. Only recently have municipalities begun to acknowledge that land use patterns affect a principle public health concern — obesity. The built environment

Table 5. Summary of Ethnographic Observation of After-School Snacking Behavior

\begin{tabular}{|c|c|c|c|c|}
\hline School (\# of subjects observed) & $\begin{array}{l}\text { Fast Food } \\
\text { Outlet Type }\end{array}$ & "Typical" Snacka & $\begin{array}{l}\text { Average Calories } \\
\text { Consumed \& \% of } \\
\text { Daily Recommended } \\
\text { Allowance }^{b}\end{array}$ & $\begin{array}{l}\text { Average Total Fat } \\
\text { (in grams) of Snack } \\
\& \% \text { of Daily Rec- } \\
\text { ommended } \\
\text { Allowance }^{c}\end{array}$ \\
\hline San José High Academy (4) & Pizza & Pizzad & $1,371 / 57.1 \%$ & $54 / 75 \%$ \\
\hline Overfelt High School (7) & Joffee house & $\begin{array}{l}\text { Coffee beverage (large size, ice- } \\
\text { blended) }\end{array}$ & $520 / 21.7 \%$ & $18 / 24.6 \%$ \\
\hline Prospect High School (7) & Hamburger & $\begin{array}{l}\text { Cheeseburger or chicken sandwich, } \\
\text { small fries, medium soda }\end{array}$ & 854 / 35.6\% & 33 / 45.3\% \\
\hline Cupertino High School (12) & Sandwich & Sandwich (large) & $1,013 / 42.2 \%$ & 49 / 68.2\% \\
\hline \multicolumn{5}{|c|}{$\begin{array}{l}\text { Notes: } \\
\text { a Each subject's order was recorded in detail. However, for purposes of this summary, we provide an example of the typical order. } \\
\text { b For each subject's order, the total caloric content was obtained from information published by the fast food outlet. The percent of daily } \\
\text { recommended allowance was based on an average } 2,400 \text { calorie diet for } 14 \text { to } 18 \text { year olds as published by the U.S. Department of Healtr } \\
\text { and Human Services. } \\
\text { c For each subject's order, the total fat content was obtained from information published by the fast food outlet. The total daily allowance } \\
\text { for fat should not exceed a median value of } 30 \% \text { of total calories per day, or } 72 \text { grams of fat for children age } 4-18 \text {. } \\
\text { d At this outlet, most food was purchased for consumption by more than one person. For each eight-slice pizza, an estimate of } 2.67 \text { slices } \\
\text { per person was assumed. In one case, a large order slightly skewed the results summary, as it included multiple pizzas plus other } \\
\text { consumables and was a take-out order, which made it difficult to assess how many people would be consuming the meal. }\end{array}$} \\
\hline
\end{tabular}


affects the public's ability to safely bicycle and walk throughout a community. Further, access to healthy and unhealthy food affects the nutritional choices available to a community.

The relationship between public health and planning is complex, but our research provides some initial evidence to suggest that Santa Clara County may be an obesogenic environment. Our geospatial analysis clearly shows that fast food outlets are clustered near high schools with higher obesity rates (as measured by percent of students not within an HFZ) in the secondary school food environment. As the schools' obesity rate increases, the number of nearby fast food outlets also increases. Furthermore, ethnographic observation confirms that students patronize these outlets and make poor nutritional choices. Previous research has suggested that the degree of commercialization in the secondary school food environment may be the cause of clustering near schools (Austin et al., 2005; Simon et al., 2008; Zenk and Powell, 2008). Degree of commercialization alone does not necessarily lead to fast food clustering, however. Simon and colleagues (2008) found that in comparably commercialized neighborhoods, income level dictated the concentration of fast food outlets. Lower income commercialized neighborhoods had higher concentrations of fast food outlets.

Academic and popular literature often postulates that fast food outlet chains intentionally target locations with close proximity to youth, even though no studies published to date have proven this theory. There is, however, a basis for this argument. Ray Kroc, founder of McDonald's, states in his book Grinding It Out: The Making of $M c D o n a l d$ 's that "back in the days when we first got a company airplane, we used to spot good locations for McDonald's stores by flying over a community and looking for schools and church steeples" (Kroc, 1992). Although only six of the 90 McDonald's in Santa Clara County are within 800 meters of a school, this ubiquitous chain has a franchise within 1.66 miles $(2.67 \mathrm{~km})$ of every high school in the county. According to Walton, Pearce, and Day (2009), children exposed to fast food outlets and to fast food advertising billboards along their route to school are more likely to make unhealthy food choices at school. Thus, limiting access to fast food outlets and restricting advertising billboards within this larger school food environment may provide important health benefits to children.

Our ethnographic research also highlights some key opportunities for policy intervention. It is not just the presence of fast food outlets in close proximity to schools that is a concern, but also the choices that individuals make when patronizing these establishments. Menu labeling is one policy option that might prove effective. A 2010 study by Tandon, Wright, Zhou, Rogers, and Christakis finds that parents chose hypothetical meals for their children with 102 fewer calories on average when presented with caloric information on the menus. California passed a law in 2008 requiring all restaurants with more than 20 outlets to print calorie information on menus, and the new national health care law includes a menu-labeling provision. Studies on the impacts of menu labeling, however, are limited, and considerably more research is needed. Consumer education is an essential piece of the very complex puzzle of the relationship between the built environment, behaviors, and public health.

A variety of policy tools can be used to regulate a municipality's retail food environment. The California cities of Calistoga and Carmel-by-the-Sea have banned fast food outlets entirely, and the city of Los Angeles adopted a fast food moratorium for a specific neighborhood that had an excessive concentration of fast food outlets. However, this approach is politically challenging. Encouraging retail outlets with healthy food is more palatable, while condition, incentive-based, and/or performance zoning can be used to encourage the development of full-service grocery stores and/or farmers' markets. A city's general or comprehensive plan is also an effective tool to promote a healthier built environment. Several California cities, including Richmond, Benicia, and Watsonville, as well as Marin County, have incorporated health elements into their general plans. The city of San Francisco has some progressive policies related 
to public health and planning that can be used as models for other communities. A team of researchers from the San Francisco Department of Public Health developed a metric to evaluate health needs in urban development, called the Healthy Development Measurement Tool. It addresses a wide range of issues, from transportation infrastructure to social cohesion, and it includes a means to assess the retail food environment and residents' access to healthy food resources. However, this approach is voluntary and primarily focuses on large-scale residential or mixed-use developments. Truly effective policies to reduce obesogenic environments and promote healthy eating behaviors among school-age children will require a multifaceted approach combining public education campaigns and enforceable policies.

Despite some limitations of our research due to a fairly small sample size of 41 high schools and limited resources to conduct ethnographic observations, we believe our findings are relevant and contribute to the existing body of literature on the relationship between the built environment and public health. Evidence strongly supports the conclusion that geospatial clustering of fast food outlets exists within the secondary school food environment in Santa Clara County. In addition, our ethnographic research highlights that high school students make some poor nutritional choices and consume a significant number of calories and fat grams in their after-school snacks. Future research could explore this latter point in more depth.

\section{References}

ArcGIS (version 9.2) [Computer software]. Redlands, California: ESRI.

Ashe, M., Feldstein, L. M., Graff, S., Kline, R., Pinkas, D., \& Zellers, L. (2007, Spring). Local venues for change: Legal strategies for healthy environments. Journal of Law, Medicine \& Ethics, 35(1), 138-147. http://dx.doi.org/10.1111/j.1748-720X.2007. 00118.x

Ashe, M., Jernigan, D., Kline, R., \& Galaz, R. (2003). Land use planning and the control of alcohol, tobacco, firearms, and fast food restaurants. American Journal of Public Health, 93(9), 1404-1408. http://dx.doi.org/10.2105/AJPH.93.9.1404
Austin, S., Bryn, S. J., Melly, M. S., Brisa, N., Sanchez, A., Patel, B. A., Buka, S., \& Gortmaker, S. L. (2005). Clustering of fast-food restaurants around schools: A novel application of spatial statistics to the study of food environments. American Journal of Public Health, 95(9), 1575-1581. http://dx.doi.org/ 10.2105/AJPH.2004.056341

Bernard, H. R. (2002). Research methods in antbropology: Qualitative and quantitative approaches (3rd ed.). Walnut Creek, California: AltaMira Press.

Black, J. L., \& Macinko, J. (2008). Neighborhoods and obesity. Nutrition Reviews, 66(1), 2-20. http://dx.doi. org/10.1111/j.1753-4887.2007.00001.x

California Department of Education (CDE). (n.d.). California Physical Fitness Test. Retrieved from http://data1.cde.ca.gov/dataquest/page2.asp?level $=$ School\&subject $=$ Fit Test\&submit1 $=$ Submit

Cummins, S., Petticrew, M., Higgins, C., Findlay, A., \& Sparks, L. (2005). Large scale food retailing as an intervention for diet and health: Quasi-experimental evaluation of a natural experiment. Journal of Epidemiology and Community Health, 59(12), 10351040. http://dx.doi.org/10.1136/jech.2004.029843

Currie, J., DellaVigna, S., Moretti, E., \& Pathania, V. (2010). The effect of fast food restaurants on obesity. American Economic Journal: Economic Policy, 2(3), 32-63. http://dx.doi.org/10.1257/pol.2.3.32

Davis, B., \& Carpenter, C. (2009). Proximity of fastfood restaurants to schools and adolescent obesity. American Journal of Public Health, 99(3), 505-510. http://dx.doi.org/10.2105/AJPH.2008.137638

Davis, L. B. (2008). Geographic placement, social identification, and consumption: $A$ study of fast-food placement around schools and youth obesity (Doctoral dissertation). Retrieved from ProQuest Dissertations and Theses database. (UMI No. 3296254).

Day, P. L., \& Pearce, J. (2011). Obesity-promoting food environments and the spatial clustering of food outlets around schools. American Journal of Preventative Medicine, 40(2), 113-121. http://dx.doi. org/10.1016/i.amepre.2010.10.018

Finkelstein, E. A., Trogdon, J. G., Cohen, J. W., \& Dietz, W. (2009). Annual medical spending attributable to obesity: Payer-and service-specific estimates. Health Affairs, 28(5), 822-831. http://dx.doi.org/10.1377/hlthaff.28.5.w822

French, S. A., Story, M., Neumark-Sztainer, D., Fulkerson, J. A., \& Hannan, P. (2001). Fast food restaurant use among adolescents: Associations with nutrient intake, food choices and behavioral and psychosocial variables. International Journal of Obesity, 25(12), 1823-1833. http://dx.doi.org/ $\underline{10.1038 / \text { sj.ijo. } 0801820}$ 
Guthrie, J. F., Lin, B.-H., \& Frazao, E. (2002). Role of food prepared away from home in the American diet, 1977-78 versus 1994-96: Changes and consequences. Journal of Nutrition Education and Behavior, 34(3), 140-150. http://dx.doi.org/ 10.1016/S1499-4046(06)60083-3

Hedley, A. A., Ogden, C. L., Johnson, C. L., Carroll, M. D., Curtin, L. R., \& Flegal, K. M. (2004). Prevalence of overweight and obesity among US children, adolescents, and adults, 1999-2002. Journal of the American Medical Association, 291(23), 2847-2850. http://dx.doi.org/10.1001/jama.291.23.2847

Hellmich, N. (2009, November 17). Rising obesity will cost U.S. health care $\$ 344$ billion a year. US $A$ Today. Retrieved from http://www.usatoday.com/ news/health/weightloss/2009-11-17-futureobesity-costs N.htm

Howard, P. H., Fitzpatrick, M., \& Fulfrost, B. (2011). Proximity of food retailers to schools and rates of overweight ninth graders: An ecological study in California. BMC Public Health, 11, 68. http://dx.doi.org/10.1186/1471-2458-11-68

Kroc, R. (1992). Grinding It Out: The Making of McDonald's. New York: St. Martin's Paperbacks.

Lamerz, A., Kuepper-Nybelen, J., Wehle, C., Bruning, N., Trost-Brinkhues, G., Brenner, H., Hebebrand, J., \& Herpertz-Dahlmann, B. (2005). Social class, parental education, and obesity prevalence in a study of six-year-old children in Germany. International Journal of Obesity, 29, 373-380. http://dx.doi.org/10.1038/sj.ijo.0802914

Maddock, J. (2004). The relationship between obesity and the prevalence of fast food restaurants: Statelevel analysis. American Journal of Health Promotion, 19(2), 137-143.

McMillan, T. E. (2009, May). Walking and biking to school, physical activity and health outcomes. Research Brief, Active Living Research, Robert Woods Johnson Foundation. Retrieved from http://www.activelivingresearch.org/files/ ALR Brief Active'Transport.pdf

Mokdad, A. H., Marks, J. S., Stroup, D. F., \& Gerberding, J. L. (2004). Actual causes of death in the United States, 2000. Journal of the American Medical Association, 291(10), 1238-1245. http://dx.doi.org/10.1001/jama.291.10.1238
Mokdad, A. H., Marks, J. S., Stroup, D. F., \& Gerberding, J. L. (2005). Correction: Actual causes of death in the United States, 2000. Journal of the American Medical Association, 293(3), 293. http://dx.doi.org/10.1001/jama.293.3.293

Nielsen, S. J., Siega-Riz, A. M., \& Popkin, B. M. (2002). Trends in food locations and sources among adolescents and young adults. Preventive Medicine, 35(2), 107-113. http://dx.doi.org/10.1006/ pmed.2002.1037

Neumark-Sztainer, D. (2009). Preventing obesity and eating disorders in adolescents: What can health care providers do? Journal of Adolescent Health. 44(3), 206-213. http://dx.doi.org/10.1016/j.jadohealth. 2008.11.005

Neumark-Sztainer, D., French, S. A., Hannan, P. J., Story, M., \& Fulkerson, J. A. (2005). School lunch and snacking patterns among high school students: Associations with school food environment and policies. International Journal of Behavioral Nutrition and Physical Activity, 2, 14. http://dx.doi.org/10.1186/ 1479-5868-2-14

Neumark-Sztainer, D., Story, M., Perry, C., \& Casey, M. A. (1999). Factors influencing food choices of adolescents: Findings from focus-group discussions with adolescents. Journal of the American Dietetic Association, 99(8), 929-937. http://dx.doi.org/ 10.1016/S0002-8223(99)00222-9

Robert Wood Johnson Foundation. (2010, May). Overweight and obesity among Latino youths. Retrieved from http://www.rwjf.org/files/research/ 20100512lhclatino.pdf

Samia Mair, J., Pierce, M. W., \& Teret, S. P. (2005, October). The use of zoning to restrict fast food outlets: $A$ potential strategy to combat obesity. The Center for Law $\&$ The Public's Health. Retrieved from http://www.publichealthlaw.net/Zoning $\% 20$ Fast $\% 20$ Food $\% 20$ Outlets.pdf

Santa Clara County. (2005). 2005 Santa Clara County children's report: Key indicators of well-being. Retrieved from http://storage.ugal.com/3283/childrens report 2005.pdf

Simon, P. A., Kwan, D., Angelescu, A., Shih, M., \& Fielding, J. E. (2008). Proximity of fast food restaurants to schools: Do neighborhood income and type of school matter? Preventive Medicine, 47(3), 284-288. http://dx.doi.org/10.1016/j.ypmed. $\underline{2008.02 .021}$ 
Stein, K. (2006). Healthful fast foods not part of healthful revenue. Journal of the American Dietetic Association, 106(3), 344-345. http://dx.doi.org/ 10.1016/j.jada.2006.01.023

Story, M., \& French, S. (2004). Food advertising and marketing directed at children and adolescents in the US. International Journal of Behavioral Nutrition and Physical Activity, 1, 3. http://dx.doi.org/10.1186/ 1479-5868-1-3

Sturm, R. (2008). Disparities in the food environment surrounding US middle and high schools. Journal of the Royal Institute of Public Health, 122(7), 681-690.

Swain, B. (2011). Coffee, caffeine \& children. Lance Armstrong Foundation. Retrieved from http://www.livestrong.com/article/449828coffee-caffeine-children/

Tandon, P. S., Wright, J., Zhou, C., Rogers, C. B., \& Christakis, D. A. (2010). Nutrition menu labeling may lead to lower-calorie restaurant meal choices for children. Pediatrics, 125(2), 244-248. http://dx.doi.org/10.1542/peds.2009-1117

U.S. Bureau of Labor Statistics. (2011). Education pays... Retrieved from http://www.bls.gov/emp/ ep chart 001.htm

U.S. Census. (n.d.). State and County Quick Facts. Retrieved April 17, 2009, from http://quickfacts. census.gov/qfd/states/06/06085.html

U.S. Census Bureau. (2011). 2010 Census. Retrieved from http://factfinder2.census.gov/faces/tableservices/ jsf/pages/productview.xhtml?pid=DEC 10 PL G $\underline{\text { CTPL2.CY07\&prodType }=\text { table }}$
U.S. Census Bureau. (2010). Estimated annual sales of U.S. retail and food services firms by kind of business: 1992 through 2008. Retrieved from http://www2.census. gov/retail/releases/historicalarts/2008 ARTS.pdf

U.S. Department of Health and Human Services. (2005). Overweight and physical activity among children: A portrait of states and the nation 2005. (The National Survey of Children's Health). Retrieved from http://mchb.hrsa.gov/overweight/printit.htm

Variyam, J. N. (2001). Overweight children: Is parental nutrition knowledge a factor? Food Review, 24(2), 18-22.

Walton, M., Pearce, J., \& Day, P. (2009). Examining the interaction between food outlets and outdoor food advertisements with primary school food environments. Health and Place, 15(3), 841-848.

http://dx.doi.org/10.1016/j.healthplace.2009. $\underline{02.003}$

White, M. (2007, March). Food access and obesity [Supplement S1]. Obesity Reviews, 8, 99-107. http://dx.doi.org/10.1111/j.1467-789X.2007. 00327.x

Zenk, S. N., \& Powell, L. M. (2008). US secondary schools and food outlets. Health and Place, 14(2), 336-346. http://dx.doi.org/10.1016/j.healthplace. $\underline{2007.08 .003}$ 